\title{
Distribution and Regeneration Status of Cordia africana (Lam.) Tree in Agroforestry Practices along Agroecology and Farmers' Wealth Status in Sidama Zone Southern Ethiopia
}

\author{
Latamo Lameso Lelamo ${ }^{1, *}$, Abdo Wudad Kemal ${ }^{2}$ \\ ${ }^{1}$ Department of Natural Resource Management, University of Kebri Dehar, P.O. Box 250, Kebri Dehar, Ethiopia \\ ${ }^{2}$ Department of Geography and Environmental Studies, University of Kebri Dehar, P.O. Box 250, Kebri Dehar, Ethiopia
}

Received March 10, 2021; Revised April 13, 2021; Accepted June 6, 2021

\section{Cite This Paper in the following Citation Styles}

(a): [1] Latamo Lameso Lelamo, Abdo Wudad Kemal, "Distribution and Regeneration Status of Cordia africana (Lam.) Tree in Agroforestry Practices along Agroecology and Farmers' Wealth Status in Sidama Zone Southern Ethiopia," Universal Journal of Agricultural Research, Vol. 9, No. 3, pp. 70 - 78, 2021. DOI: 10.13189/ujar.2021.090302.

(b): Latamo Lameso Lelamo, Abdo Wudad Kemal (2021). Distribution and Regeneration Status of Cordia africana (Lam.) Tree in Agroforestry Practices along Agroecology and Farmers' Wealth Status in Sidama Zone Southern Ethiopia. Universal Journal of Agricultural Research, 9(3), 70 - 78. DOI: 10.13189/ujar.2021.090302.

Copyright $(2021$ by authors, all rights reserved. Authors agree that this article remains permanently open access under the terms of the Creative Commons Attribution License 4.0 International License

\begin{abstract}
Cordia africana (Lam.) is one of the indigenous multipurpose tree species which is being endangered and suffering a lot from overexploitation. Nowadays agroforestry is taken as potential ecosystem for counteracting extinction of this tree through providing complementary habitat in Ethiopia. Therefore, this study aimed to identify distribution and regeneration status of Cordia africana tree in agroforestry practices with respect to agroecologies and farmers wealth status. Selection of respondents was done based on the wealth status of households for tree inventory. The total households were categorized into three main wealth categories as wealthy, medium and poor. Accordingly, 72 households were selected by taking three households randomly across wealth categories from eight different villages. Then, tree inventory was done from three different agroforestry practices in each 72 households with big plot size of $20 \mathrm{~m} \times 20 \mathrm{~m}$ and $5 \mathrm{mx} 5 \mathrm{~m}$ nested subplots. The results of the study revealed that mean stems of trees were significantly higher $(p<0.05)$ in enset- tree based agroforestry practice followed by coffee-tree based practice in two agroecological setting. The study also found that the number of stems per plot and per hectare was significantly higher $(\mathrm{p}=0.0001)$ in midland agroecology than lowland agroecology. The results also showed that the mean stems
\end{abstract}

of trees were significantly higher $(\mathrm{p}<0.05)$ from rich wealth classes in two agroecological settings. There is also significant variation of regeneration status of Cordia africana tree with respected to agroecology and different agroforestry practices. Finally, the study suggests that regeneration status of Cordia africana tree should be assisted and facilitated for the sustainability of this valuable tree species.

Keywords Agroecology, Agroforestry, Distribution, Endangered, Multipurpose, Regeneration Status

\section{Introduction}

Integration of trees on farms are characteristic of a large part of the Ethiopian agricultural landscape today, while tree species management intensity and distribution varying with agro-ecological conditions principally defined by rainfall, altitude and soil type [16]. It is common for farmers to manage natural regenerating multipurpose trees within agricultural fields by protecting seedlings and young trees, mostly native species that have germinated from soil seed banks. From these native multipurpose tree 
species, Cordia africana (Lam.) (C.africana) is an indigenous tree species which is extensively adopted and managed by farmers, as a dominant feature of agricultural landscapes in the sub-humid zone of Ethiopia [5].

C.africana (Lam.) is a deciduous tree which belongs to the family of Boraginaceae and widely distributed on the area with an annual rainfall of $700-2000 \mathrm{~mm}$ and at altitudes between 550 - 2600 meters above sea level (masl) from South Africa to Saudi Arabia and Yemen [15]. C.africana prefers regions with relatively high rainfall and sufficiently warm climate. It can also grow under drier climatic conditions, by minimizing its water consumption through shading its leaves or by closing its stomata [21].

C.africana is native to Angola, the Democratic Republic of Congo, Eritrea, Djibouti, Ethiopia, Guinea, Ghana, Malawi, Kenya, Mozambique, South Africa, Sudan, Tanzania, Uganda, Zimbabwe, Saudi Arabia and Yemen [15]. In West Africa, this tree species is said to be restricted to a habitat pertaining to cool and moist upland slopes (montane) and submontane habitats. C.africana spread widely in broadleaved Afromontane Rain Forests, undifferentiated Afromontane Forests and in riverine forests as well as in the western lowlands in Ethiopia. It can also grown open places in the forest, forest edges, in forest remnants around churches and other traditionally protected areas, as isolated trees in grassland and cultivated fields [2]. Dry, moist and wet weyna dega agro-ecological zone are areas where C. africana tree grows well in Ethiopia [7]. In southern parts of Ethiopia farmers integrated, manage and use it with coffee and enset in an effective agroforestry system as shade tree that provides them with many useful products and services [25].

The current distribution, populations and habitat of $C$. africana was severely affected by deforestation, fragmentation and selective logging [2]. Severe natural forest destruction in Ethiopia has forced the tree to have scattered rate in uneven natural forest, on farmlands, in graveyards and church compounds particularly in the northern part of the country [2]. It is evidently shown by its scarce distribution in Ethiopia except in some protected coffee forests [10]. The over exploitation of this tree for its timber production was reported in Ethiopia as an important factor threatening the existence of the species [9]. Thus, the demand for wood of C.africana by users of its timber and timber products is enormous. This high demand has caused a rapid depletion of the species and it is now one of the Ethiopian most threatened tree species [26]. Because of this, conservation priority has been identified nationally by using in-situ and ex-situ conservation in Ethiopia [26].
Field gene banks, botanical gardens and duplicate gene banks along with preservation centers are being established in various localities to supplement the in-situ conservation sites. Districts such as Lephis, Farta, Debre Tabor and Arsi Nagelle are the areas where ex-situ sites have been established in Ethiopia [20].

Managing C.africana in agroforestry farming systems is one of the best options for maintaining sustainability of this tree species. Farmers in southern Ethiopia retain C.africana for maintaining soil fertility in enset-coffee based agroforestry [32]. In Sidama, it is one of the multipurpose trees mostly used in agroforestry systems by farmers. It is used for different socio-economic benefits and for soil improvement as shade tree for coffee and other land use systems for the long time ago mostly in midland and lowland agroecologies. In Ethiopia, some researchers have made studies on the different aspects of C.africana tree $[5,8,2,20,26]$, but there is a shortage of studies conducted to identify its distribution and regeneration status in different agroecological gradients and farmers' wealth status for species sustainability analysis. There is also scarcity of study conducted to identify regenerations status of this tree in different agroforestry practices. Shortage of such targeted studies may leads to more extinction of this tree and loss of associated benefits. For this reason, this study is initiated to identify distribution and regeneration status of C.africanain Sidama zone, southern Ethiopia to assist in the proper utilization, management and conservation.

\section{Material and Methods}

\subsection{Description of the Study Area}

This study was conducted in Sidama zone southern Ethiopia. The Sidama zone is found at the coordinate of $38^{\circ} 27^{\prime} 43^{\prime \prime} \mathrm{E}$ and $39^{\circ} 31^{\prime} 78^{\prime \prime} \mathrm{E}$ longitude and $5^{\circ} 45^{\prime} 33^{\prime \prime} \mathrm{N}$ and $6^{\circ} 45^{\prime} 71$ " N latitude with total area of $10,000 \mathrm{~km}^{2}$. It lays between Hawassa town in the north and Dilla town in the south, spread out in a cone-shaped area in the middle of southern Ethiopia (Figure 1). It has three agro-ecological zones namely highland (Dega) $(16 \%)$ ranging from an elevation of 2500 to 3500 masl, midland (Woinadega) (54\%) from 1500 to 2500 masl and lowland (Qola) (30\%) $500 \mathrm{~m}$ to 1500 masl. The soil type in the study area dominantly classified as Nitosols and Eutric nitosols [29]. 


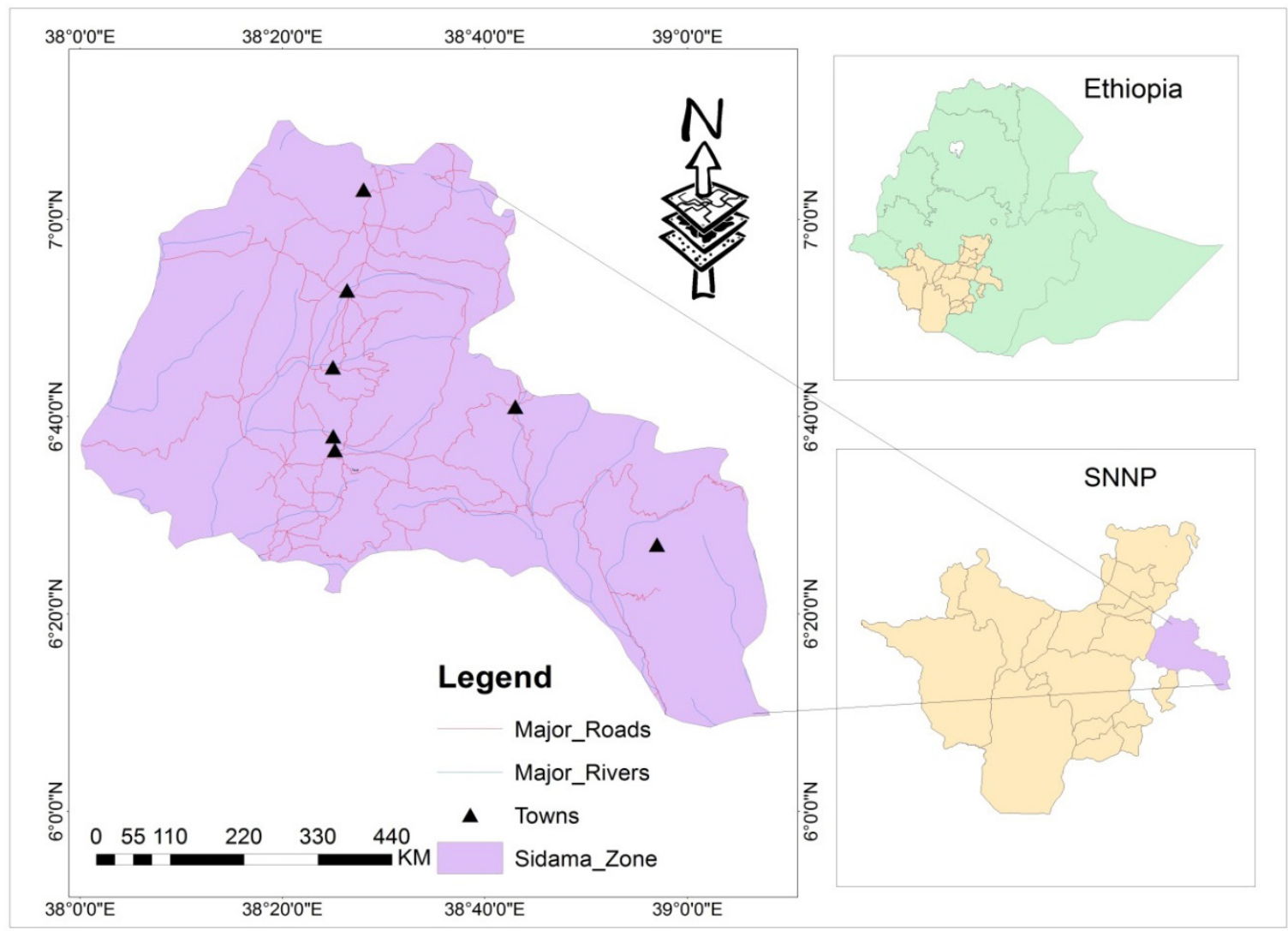

Figure 1. Map of study area

\subsection{Research Design}

\subsubsection{Sampling techniques and sample size determination}

In the study, two districts Malga from midland agroecology and Hawelatula from lowland agroecology were selected purposively as a result of C.africana is not grown in the highland agro-ecology $[15,7]$. Thereafter, two kebeles per districts are considered for the study.

The selection of households (HHs) was based on the wealth classes of households, because of the reason that management of tree in agricultural landscape depends on socio-economic condition or wealth status of households [12]. A total of eight villages were considered by selecting randomly two villages from each kebele. After that all households under each village were categorized into three main wealth categories as rich, medium and poor based on local wealth ranking criteria of each village by adapting techniques modified by [13]. The criteria such as land size, livestock owned and occupation were considered for wealth categorization following approach indentified by $[23,1]$ in each village. In order to get a representative sample from villages, three households from each wealth class were selected randomly. Based on this procedure, a total of 72 households were selected for tree inventory.

\subsubsection{Tree inventory procedures}

Following personal field observations and studies of $[4$,
24] baseline information was generated for understanding of the existing agroforestry practices. Based on these, three as coffee-enset-tree based, coffee-tree based and enset-tree based agroforestry practices were selected.

Within the farms of each selected households, one random plots of $20 \mathrm{~m} \times 20 \mathrm{~m}$ size was laid (one plot per practice) following method of [5] in each three identified agroforestry practices. The plot sizes of $20 \mathrm{~m} \times 20 \mathrm{~m}$ were used for measuring trees of $>5 \mathrm{~cm}$ diameter size classes at about $1.3 \mathrm{~m}$ height from the ground. In addition to this, four subplots measuring $5 \mathrm{~m} \times 5 \mathrm{~m}$ were nested at the corners of each bigger plot following methods of [17, 28]. From these subplots density of seedlings and sapling were recorded for identification of regeneration status.

In this study, large trees were trees with DBH of $>25 \mathrm{~cm}$ and above, small poles $>5-25 \mathrm{~cm}$ and saplings were the young trees with diameter size class of $2-5 \mathrm{~cm}$ whereas seedlings were those with diameter size class $<2 \mathrm{~cm}$ [22]. Based on this, the number of total stem per plot, collar diameter for seedlings at the base, diameter at the height $30 \mathrm{~cm}$ for saplings and DBH at about $1.3 \mathrm{~m}$ from the ground for trees and total height were measured and recorded. Calipers and hypsometers were used to measure DBH and tree total height, respectively.

\subsubsection{Statistical Analyses}

Difference on the distribution of tree along agroecology 
and farmers wealth status were examined by using one way ANOVA with Statistical Package for Social Science (SPSS). Turkeys' test was used to test significance difference among any two means to identify variation. Regeneration status of tree was evaluated in two agroecological areas and agroforestry practices by counting the total number of individual stems. Total counted stems were grouped into different arbitrary diameter classes and height classes in each agroecology.

\section{Results and Discussion}

\subsection{Distribution of Cordia africana tree}

\subsubsection{Distribution of Cordia africana tree in agroforestry practices}

Coffee-enset-tree based, coffee-tree based and enset-tree based were major agroforestry practice being used for planting and retaining C.africana tree. Even if three practices were being used for planting and retaining this tree, there are variations on distribution and abundance of trees in the practices. Mean number of stems per plot and per hectare (ha) from enset-tree based agroforestry practice is significantly different $(\mathrm{p}<0.05)$ from coffee-enset-tree based practice in two agroecologies. This is because of enset-tree based agroforestry practice has largest mean number of stems per plot and per hectare $(65.30 \pm 38.40$ and $56.94 \pm 41.60)$, followed by coffee-tree based practice $(59.72 \pm 43.62$ and $39.60 \pm 44.90)$ in midland and lowland agroecologies, respectively (Table 1). But coffee-tree based and coffee-enset-tree based agroforestry practices have no significant difference in two agroecological zones.

Based on the result presented on (Table 1), a large number of stems were recorded from enset-tree based agroforerstry practice in two agroecological areas. This shows that enset-tree based agroforerstry practice is more preferred agroforestry practice for planting and retaining C.africana tree in the study area. This might be due to farmers' preference of enset-tree based agroforestry practice for planting and retaining C.africana tree with respect to its coexistence with enset and coffee. As confirmed by $[12,26]$ farmers used different criteria for different tree species which are the ability of the tree species to compatibility with other crops, providing different products and services and coppicing ability. Similar finding from [11] also shown that woody species are selected according to their value as fertilizers, low competition and being food for humans and feed for animals.

\subsubsection{Distribution of Cordia africana tree along two agroecological zones}

In the study sites, C.africana trees were recorded from sampled plots in three selected agroforestry practices from midland and lowland agroecology. The overall mean numbers of stems per plot and per hectare are $(2.31 \pm 1.54)$ and $(57.75 \pm 38.44)$ in midland agroecology and (1.59 \pm 1.70$)$ and (39.57 \pm 41.60$)$ in lowland agroecology, respectively (Table 2). The number of stems per plot and per hectare in midland agroecology was significantly higher $(p=0.0001)$ than lowland agroecology. Result presented on (Table 2) indicated that the presence and distribution of C.africana tree depends on agroecological condition of the study sites. This was in line with study conducted in western Kenya by [14] who reported that tree integration on smallholder farmers' plots vary in terms of environment and agroecology.

Table 1. Mean number of stems under three agroforestry practices

\begin{tabular}{|c|c|c|c|}
\hline Agroecology & Agroforestry practices & Number of stems/plot & Number of stems/ha \\
\hline & & Mean SD & Mean SD \\
\hline \multirow{4}{*}{ Midland } & Coffee-enset-tree based & $1.92^{\mathrm{ab}} \pm 1.60$ & $47.92^{\mathrm{ab}} \pm 31.30$ \\
\hline & Coffee-tree based & $2.40^{\mathrm{a}} \pm 1.74$ & $59.72^{\mathrm{a}} \pm 43.62$ \\
\hline & Enset-tree based & $2.61^{\mathrm{a}} \pm 1.54$ & $65.30^{\mathrm{a}} \pm 38.40$ \\
\hline & Coffee-enset-tree based & $0.90^{\mathrm{ab}} \pm 1.21$ & $22.22^{\mathrm{ab}} \pm 30.34$ \\
\hline \multirow[t]{2}{*}{ Lowland } & Coffee-tree based & $1.60^{\mathrm{a}} \pm 1.80$ & $39.60^{\mathrm{a}} \pm 44.90$ \\
\hline & Enset-tree based & $2.30^{\mathrm{a}} \pm 1.70$ & $56.94^{\mathrm{a}} \pm 41.60$ \\
\hline
\end{tabular}

Note:-Different superscript letters in the same column indicates significant difference

Table 2. Mean number of stems per plot and per ha in two agroecological zones

\begin{tabular}{ccc}
\hline Agroecology & Number of stems/plot & Number of stems/ha \\
& Mean SD & Mean SD \\
\cline { 2 - 3 } Midland & $2.31^{\mathbf{a}} \pm 1.54$ & $57.75^{\mathbf{a}} \pm 38.44$ \\
Lowland & $1.59^{\mathbf{b}} \pm 1.70$ & $39.57^{\mathbf{b}} \pm 41.60$ \\
\hline
\end{tabular}

Note:-Different superscript letters in the same column indicates significant difference 


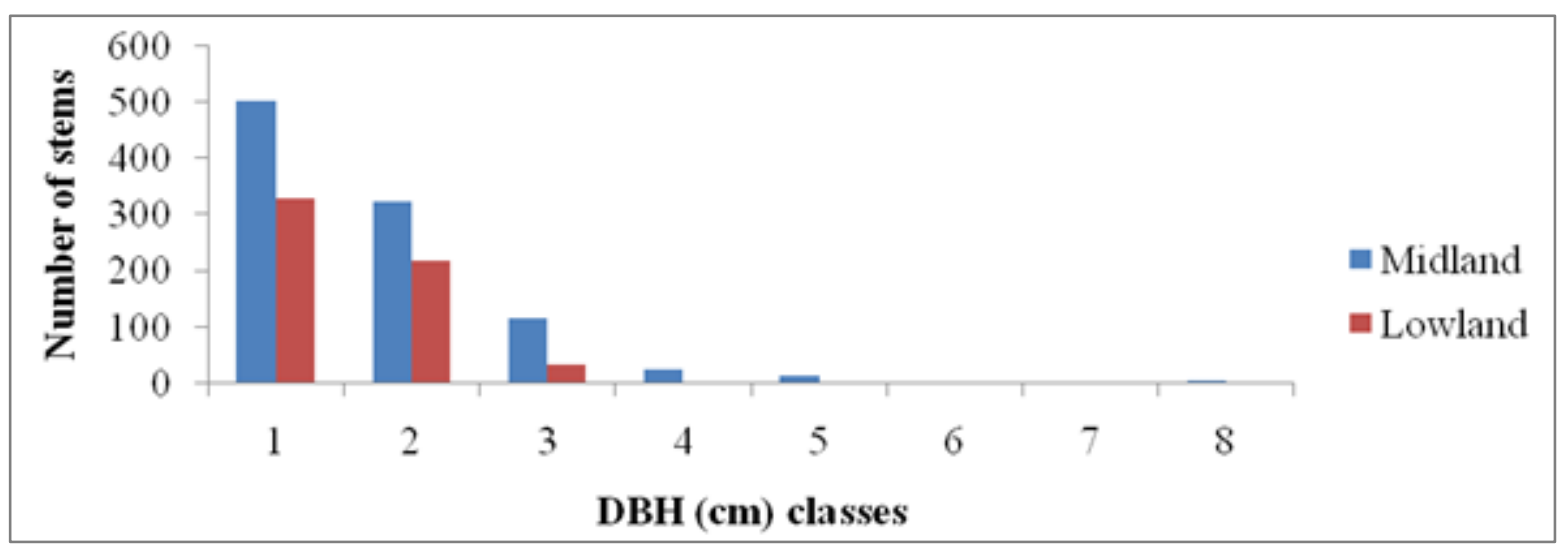

Diameter classes: $-1=5-15.9,2=16-30.9,3=31-45.9,4=46-60.9,5=61-75.9,6=76-90.9,7=91-105.9$ and $8=\geq 106$.

Figure 2. Diameter class distribution of C.africana tree in the two agroecological zones

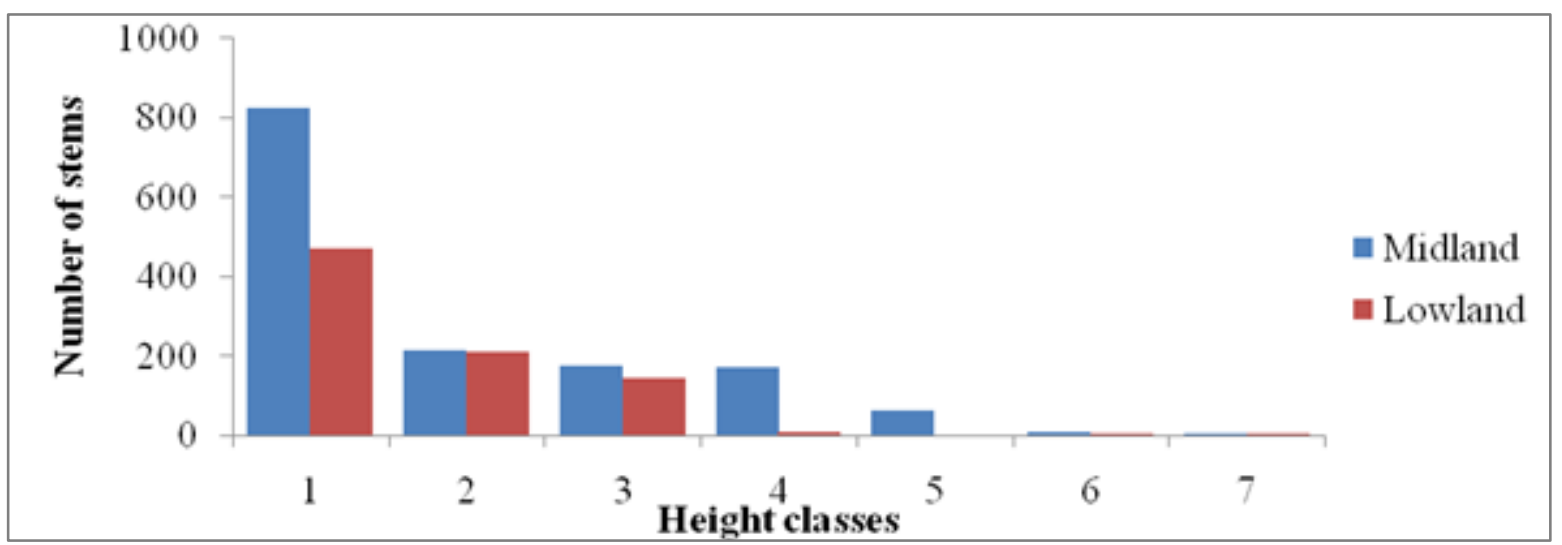

Height class (cm): $-1=0-5.9,2=6-10.9,3=11-15.9,4=16-20.9,5=21-25.9,6=26-30.9$ and $7=31-35.9$

Figure 3. Height class distribution of C.africana tree in the two agroecological zones

A total of 1461 and 833 stems above $(5 \mathrm{~cm})$ were recorded from midland and low agroecology, respectively. Diameter and height were measured from each individual stems above $(5 \mathrm{~cm})$ from plots under selected agroforestry practice. A total stems of $44.9 \%$ and $23.2 \%$ of stems were recorded under diameter class of $5-15.9 \mathrm{~cm}$ in midland and lowland agroecology, respectively. Similarly, $14.7 \%$ and $8.6 \%$ of stems were recorded under diameter class of $16-30.9 \mathrm{~cm}$ in midland and lowland agroecology respectively (Figure 2). Relatively high proportions of population in the samples were represented by small poles in two agroecological settings those belonging to the diameter class of 5-15.9 and 16-30.9cm (Figure 2).

The overall population structure of C.africana represented with a larger number of individuals in smaller diameter classes with decreasing number of individuals when tree increase in its diameter size class in two agroecology (Figure 2). As a result of this, the graphical descriptions C.africana tree distribution in the two agroecological zones followed the inverted " $\mathrm{J}$ " curve. This shows that there is the abundance in the lowest diameter class $(5-15.9 \mathrm{~cm})$ which illustrates good regeneration potential. This is due to germination of large number of seedlings during rainy season because of C.africana tree produces large amount of seed in each year. Similar finding from [30] confirm that a healthy population of any species will display a typical inverted "J-shaped" curve, which represents a high generation in the lower classes, gradually diminishing with increased size class through mortality.

A height class distribution pattern of C.africana trees in the study area was also characterized by higher population at young and middle stage than mature stage (Figure 3). Thus, the general structure of height class distribution confirms inverted $\mathrm{J}$ shaped pattern which shows the stability of population structure.

\subsubsection{Distribution of Cordia africana tree on farms of households with different wealth categories}

In addition to agroecological effects on distribution of C.africana tree, the influences of households' wealth status also tested. For this reason mean numbers of stems were determined both per plot and per hectare under each household wealth classes. In midland agroecology, both rich and medium wealth classes are significantly different from poor wealth classes $(p<0.05)$. The results on (Table 3$)$ show that mean stems per plot and per hectare for rich and medium household are not significantly different $(p>0.05)$ from each other in midland agroecology. Unlike that of midland agroecology, mean numbers of stems per plot and 
per hectare in rich wealth class is significantly different $(\mathrm{p}<0.05)$ from both medium and poor wealth classes from lowland agroecology. But both medium and poor wealth classes are not significantly different $(p>0.05)$ from each other in lowland agroecology. Based on the result presented on (Table 3), households' wealth status has influence on the distribution of C.africana in addition to agroecological variations. Generally, wealthier farmers have more mean number of trees in their agroforestry practices followed by medium wealth category in two agroecological settings.

This result is in agreement with the study of [13] who reported that wealthier smallholder household heads kept relatively more trees on their farm plots. The main reasons for this variation among different wealth classes were, most rich farmers have more resources like, land and other assets that help them for fulfilling different family members' needs. Therefore, wealthier households prolong rotation time for tree. That means waiting longer without harvesting and leaving almost all trees to grow in farm land than poor households. But this result disagrees with findings of [12], [19], who found that poor farmers had the largest number of trees per hectare compared with wealthier and medium farmers.

\subsection{Regeneration Pattern of Cordia africana Tree}

\subsubsection{Regeneration pattern of Cordia africana tree along two agroecological zone}

The presence of trees, small poles, saplings and seedlings from two agroecological settings are given on (Figure 4). In the study area, C.africana tree is categorized into different growth forms based on the current level of utilization of products from this tree which is determined by diameter class. These are seedlings $(<2 \mathrm{~cm})$, saplings $(>2-5 \mathrm{~cm}$ diameter), small poles $(>5-25.9 \mathrm{~cm})$ and large trees $(26 \mathrm{~cm}$ and above) diameter class. The mean partitioned growth forms for each regeneration size class per hectare show that $(20.1 \%)$ and $(3.5 \%)$ seedlings, $(19.7 \%)$ and $(11.8 \%)$ saplings, $(18.3 \%)$ and $(14.8 \%)$ small poles and $(9.2 \%)$ and $(2.6 \%)$ large trees in midland and lowland agroecology, respectively.

Table 3. Mean number of stems per plot and per ha under three wealth classes

\begin{tabular}{|c|c|c|c|c|}
\hline Agroecology & Kebele & HHs Wealth Status & Number of stems/plot & Number of stems/ha \\
\hline \multirow{6}{*}{ Midland } & \multirow{4}{*}{ Sintaro } & & Mean & Mean \\
\hline & & Rich & $3.60^{\mathrm{a}} \pm 1.04$ & $88.70^{\mathrm{a}} \pm 26.04$ \\
\hline & & Medium & $2.94^{\mathrm{a}} \pm 1.60$ & $73.61^{\mathrm{a}} \pm 31.50$ \\
\hline & & Poor & $1.44^{\mathrm{b}} \pm 0.78$ & $36.11^{\mathrm{b}} \pm 19.60$ \\
\hline & \multirow{3}{*}{ Kocho } & Rich & $2.30^{\mathrm{a}} \pm 2.10$ & $56.94^{\mathrm{a}} \pm 52.02$ \\
\hline & & Medium & $2.60^{\mathrm{a}} \pm 0.94$ & $63.90^{\mathrm{a}} \pm 24.60$ \\
\hline \multirow{7}{*}{ Lowland } & & Poor & $1.06^{\mathbf{b}} \pm 1.30$ & $26.40^{b} \pm 32.62$ \\
\hline & \multirow{3}{*}{ Tullo } & Rich & $3.00^{\mathrm{a}} \pm 2.28$ & $75.00^{\mathrm{a}} \pm 56.90$ \\
\hline & & Medium & $1.50^{\mathrm{b}} \pm 1.10$ & $37.50^{\mathrm{b}} \pm 27.60$ \\
\hline & & Poor & $1.56^{\mathrm{b}} \pm 1.60$ & $38.90^{b} \pm 39.50$ \\
\hline & \multirow{3}{*}{ Finchawa } & Rich & $2.06^{\mathrm{a}} \pm 1.60$ & $51.40^{a} \pm 38.80$ \\
\hline & & Medium & $0.88^{\mathrm{a}} \pm 1.13$ & $22.22^{\mathrm{a}} \pm 28.30$ \\
\hline & & Poor & $0.50^{\text {ab }} \pm 0.90$ & $12.50^{\mathrm{ab}} \pm 21.44$ \\
\hline
\end{tabular}

Note:-Different superscript letters in the same column indicates significant difference

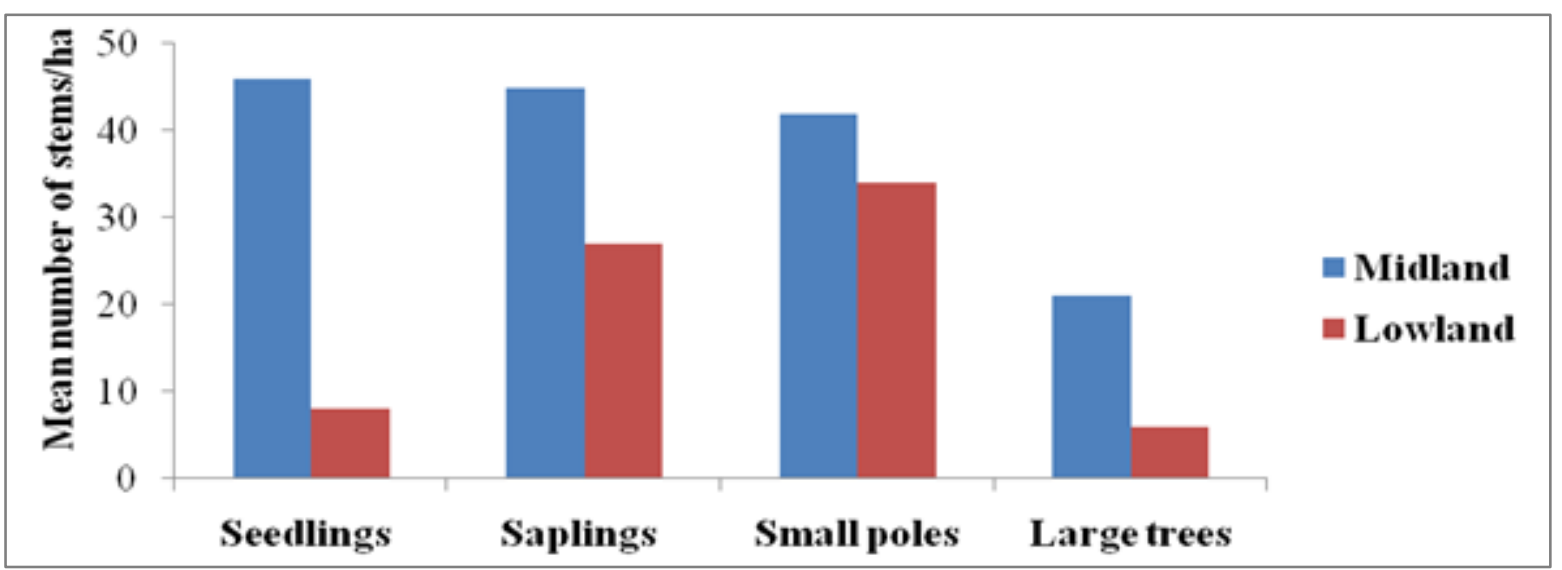

Figure 4. Mean growth form distribution of C.africana trees/ha in two agroecologies 
Maximum availability of tree was observed in midland agroecology under each growth form. It indicated that, mean number of seedlings and saplings recorded from midland agroecology were fourfold and twofold higher than that of lowland agroecology, respectively. The mean number of large trees recorded from midland agroecology was also higher than lowland agroecology.

Generally, larger numbers of stems were recorded from midland agroecology within each growth forms. The main reasons for this difference maybe variability on ecological factors such as rain fall, temperature and solar radiation and soil type in two agroecological zones. There are research evidences showing that, small changes in temperature may have drastic effects on tropical tree species distribution patterns [31]. As result presented on (Figure 4), the trees were highly declined in the higher diameter classes at diameter class of $(>26)$ in two agroecology. This is because of the removal of tree for timber and construction wood and sale for cash generation. The finding of [18] confirm that need for timber and wood and selling trees for income generation cause decline of trees under higher diameter classes.

\subsubsection{Regeneration pattern of Cordia africana tree in agroforestry practices}

The results on regeneration pattern of C.africana tree in different traditional agroforestry practices have no similarity under different growth forms. The availability of trees depends on the agroforestry practices. The average number of seedlings observed in coffee-enset-tree and coffee-tree based agroforestry practice were $32.2 / \mathrm{ha}$ and $28.5 /$ ha, respectively in midland agroecology while the availability of seedlings is very low in lowland agroecology (Figure 5 and 6). The coffee-tree based agroforestry practice has the more number of seedlings (12.7/ha) when compared with coffee-enset-tree and coffee-tree based practices in lowland agroecology. Likewise the seedlings, the availability of saplings also showed difference from availability of seedlings in coffee-enset-tree and coffee-tree based practice and slightly below seedlings in midland agroecology. It was 31.3/ha and 27.2/ha in coffee-enset-tree and coffee-tree based agroforestry practices, respectively. But the availability of saplings is twofold higher from the availability of seedlings in coffee-enset-tree and coffee-tree based practices in lowland agroecology. When compared with availability of seedlings, more number of saplings is observed under three agroforestry practices in lowland agroecology and vice versa with midland agroecology.

It is also clear from the Figures 5,6 and 7 that the more number of seedlings present on midland agroecology as compared to lowland agroecology in three practices. This was because of solar radiations which directly fall on the earth reduces the soil moisture and cause the death of seedlings during dry season in lowland agroecology. This was evidenced by the finding of [7] who reported that, direct solar radiations affect the natural regeneration and growth of tree by reducing the soil moisture and increasing temperature. To reduce such factors affecting regeneration status; assisted natural regeneration required during retaining and planting C.africana tree in low land agroecology. This is because of assisted natural regeneration increase tree density in agricultural landscapes as same time improves floristic composition of herbaceous plants [11]. In three agroforestry practices more number of small poles $(>5-25 \mathrm{~cm}$ diameter) were recorded from lowland agroecology. This is due to trees under this diameter size were only utilized for fuel wood and dead fence and retain to attain the size recommended for timber production. In addition to this C.africana tree under diameter of small poles stage were retained in the niches to provide shade for underneath crops both coffee and enset.

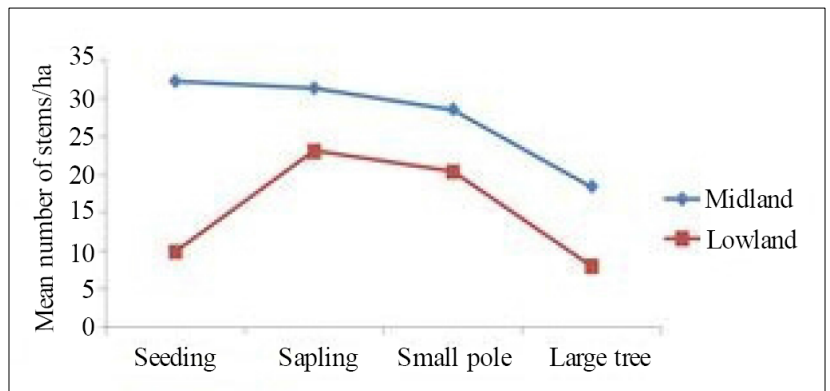

Figure 5. Mean growth form distribution of C.africana trees/ha under Coffee-enset-tree based agroforestry practice

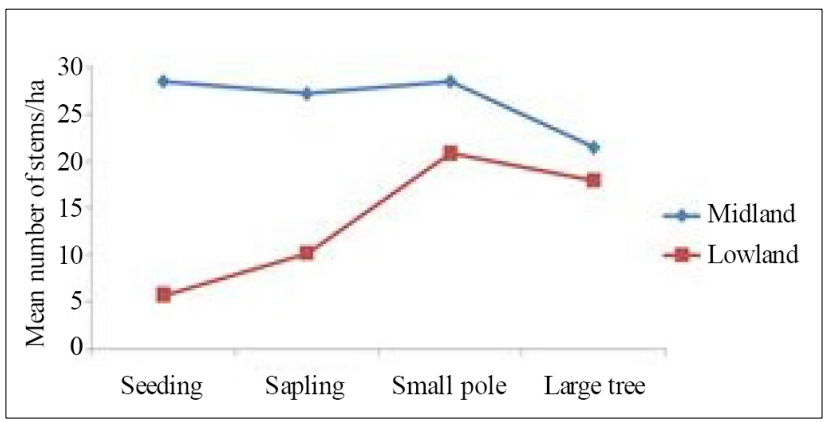

Figure 6. Mean growth form distribution of C.africana trees/ha under Coffee-tree based agroforestry practice

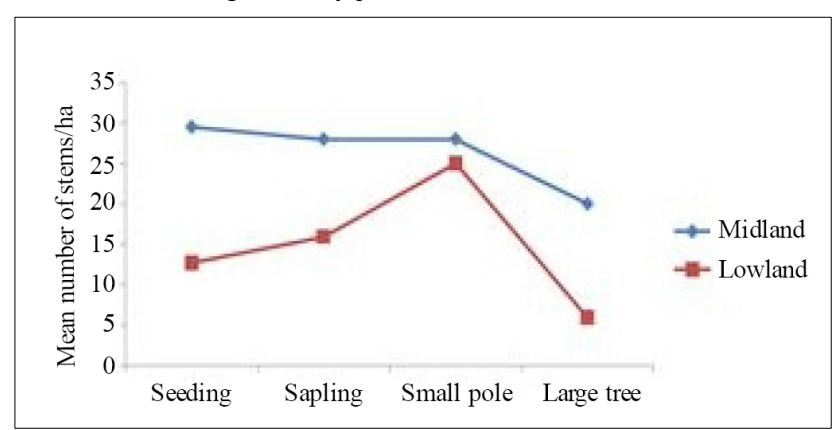

Figure 7. Mean growth form distribution of C.africana trees/ha under Enset-tree based agroforestry practices

\section{Conclusions}

C.africana is indigenous multipurpose tree in Ethiopia which provides a number of socio-economic benefits for 
farmers. It is preferred and adopted for maintaining soil fertility in agroforestry farming systems and shade tree for coffee and other land use systems for the long time ago mostly in midland and lowland agroecologies. Currently, severe natural forest destruction, over exploitation for timber production and fuel wood threatening the existence have caused a rapid depletion of this tree species in Ethiopia. In Sidama zone southern part of Ethiopia it is intensively retained and managed indigenous multipurpose tree species which is preferred by farmers. But its distribution pattern and regeneration status depend on agroecological conditions of the area, wealth status of the farmers and nature integrated agroforestry practices. Therefore, the identification of suitable agroforestry practices and agroecology is mandatory for conserving and sustaining this tree and counteracting extinction for its multipurpose benefits. Regarding to these, this study found that enset-tree based agroforestry practice is a more suitable place for retaining and planting C.africana tree, followed by coffee-tree based practice in two agroecology. The finding also shows that maximum availability of trees was observed in midland agroecology under each growth form which indicates that tree has more regeneration potential in midland agroecology. The finding also exposes that regeneration is higher in three selected agroforestry practice in midland agroecology than lowland agroecology. The results also showed that the mean stems of trees were significantly higher from rich wealth classes in two agroecological setting. Generally, the finding this study conclude that the variability on agroecological condition, agroforestry practices and wealth status of farmers have their own influence on the distribution and regeneration potential of C.africana tree in study area.

\section{Recommendations}

In order to counteract the extinction and to insure the sustainability of this important tree species as an agricultural resource, regeneration should be assisted by incorporating production of seedlings in existing nursery sites. Further studies should be undertaken on the mother tree selection for two agroecological zones. Awareness also should be created for the farmers on how to choice mother tree during selective retaining and transplanting in their agroforestry system. In addition to these, comparative studies should be done on soil physical property and other associated biotic factors those can hold back the natural regeneration of C.africana tree with respect to agroecology and agroforestry practices. And also studies focused on different yield parameters on crops grown with and without C.africana tree also should be conducted. Finally, government should support small holder farmers through free delivery of seedlings especially those have limited natural regeneration in their farmland.

\section{Declaration of Competing Interest}

The authors declare that they have no known competing financial interests or personal relationships that could have appeared to influence the work reported in this paper.

\section{Acknowledgements}

The authors acknowledge research field assistants and they are particularly grateful to the households who allow them to undertake tree inventory from their farmlands.

\section{REFERENCES}

[1] A.J. Doty, "Participatory Wealth Rankings as A Tool for Targeting and Evaluation: Monitoring and Evaluation Fellow", Village Enterprise, pp. 1-14, 2014.

[2] Abayneh D., Gailing O., R. Finkeldey, "Maintenance of Genetic Diversity in C.africana Lam., A Declining Forest Tree Species in Ethiopia", Tree Genetics \& Genomes, vol.7, no.1,pp.1-9,2011.https://doi.org/10.1007/s11295-010-03101.

[3] Abayneh D., Tamrat B., N. Bert-Ake, "Population Structure and Regeneration of Woody Species in a Broad-Leaved Afromontane Rain Forest; Southwest, Ethiopia”, Ethiopian Journal of Natural Resource, vol.5, no.2, pp.255-280, 2003.

[4] Abebe T., Wiersum K.F., Bongers F., F. Sterck, "Diversity and dynamics in homegardens of southern Ethiopia In: B. M. Kumar \& P. K. R. Nair (Eds.)", Tropical homegardens: a time-tested example of sustainable agroforestry, pp. 123-142. 2006.

[5] Abebe Y., Fisseha I., O. Mats, "Scattered Trees as Modifiers of Agricultural Landscapes: The Role of Waddeessa $(C$. africana Lam.) Trees in Bako Area, Oromia, Ethiopia", African Journal of Ecology, vol. 47, no. 1, pp.78-83.2009.https://doi.org/10.1111/j.1365-2028.2008.01 053.x.

[6] Abreha A., W. Gebrekidan, "Woody Plant Inventory and Diversity in Traditional Agroforestry of Selected Peasant Association of South Gonder Zone, North West Ethiopia", Journal of Environment and Earth Science, vol. 4, no. 15, pp.8-16, 2014.

[7] Arvind B., JRD. Manmohan, "Geometry, Distribution and Regeneration Pattern of Trees in Agroforestry Systems along Altitude and Aspects in the Upper Yamuna Region of Uttarakh and Himalaya, India", Applied Ecology and Environmental Sciences, vol. 4, no. 1, pp.15-25,2016.

[8] B. Azene, "Useful Trees and Shrubs of Ethiopia: Identification, Propagation and Management in 17 Agro-ecological Zones. Nairobi”, RELMA in ICRAF Project, 2007, pp.552.

[9] Balemie K., F. Kebebew, "Ethnobotanical study of wild edible plants in Derashe and Kucha Districts, South Ethiopia", J Ethnobiology Ethnomedicine, vol. 2, pp. 53, 
2006. https://doi.org/10.1186/1746-4269-2-53

[10]E, Behailu, "Ethno botanical Study of Traditional Medicinal Plants of Goma Wereda Jima Zone, Oromia Region Ethiopia. Doctoral dissertation, Addis Ababa University. Addis Ababa, Ethiopia”, 2010, pp. 33.

[11] Bil-Assanou I.H., Boukari D., L. Sitou, "Scaling up Assisted Natural Regeneration to Intensify Agroecologically Agrosystems Productivity”, Universal Journal of Agricultural Research vol. 8, no. 1, pp. 11-17. 2020.https://doi.org/10.13189/ujar.2020.080102

[12] Bucagu C., Vanlauwe B., MT. Van Wijk, “Assessing farmers' interest in agroforestry in two contrasting agro-ecological zones of Rwanda", Agroforest Syst, vol. 87, pp.141-158, 2013.https://doi.org/10.1007/s10457-012-9531-7

[13] EL. Crowley, "Rapid data collection using wealth ranking and other techniques. International Centre for Research in Agroforestry (ICRAF), Nairobi, Kenya”, 1997, pp.16.

[14] Erick O.W. "Smallholders farmers' perception and practices of on-farm tree species diversification in Siaya country, western Keniya. MSC thesis, Kenyatta University, Kenya', 2019.http://ir-library.ku.ac.ke/handle/123456789/19665

[15] I.B. Friis, "Forests and Forest Trees of Northeast Tropical Africa: Their Natural Habitats and Distribution Patterns in Ethiopia, Djibouti and Somalia", Her majestry's stationary office. Kew Bulletin Additional Series XV, 1992, pp.396.

[16] Gelaw A.M., Singh BR., R. Lal, "Soil Organic Carbon and Total Nitrogen Stocks under Different Land Uses in a Semi-Arid Watershed in Tigray, Northern Ethiopia", Agriculture, Ecosystems and Environment, vol.188, pp.256-263, 2014.

[17] Gerard N.G., Valentin K., Achille E.A., S. Brice, "Population Structure and Abundance of Sclerocarya birrea (A. Rich) Hochst Subsp. Birrea in Two Contrasting Land-Use Systems in Benin", International Journal of Biodiversity and Conservation, vol. 1, no. 6, pp. 194-201, 2009. https://doi.org/10.5897/IJBC.9000112

[18] Getahun Y., F. Anteneh. "Diversity and Regeneration Status of Woody Species: The Case of Keja Araba and Tula Forests, South West Ethiopia", Open Access Library Journal, vol. 3, no. 4, pp.1, 2016.https://doi.org/10.4236/oalib.1102576

[19] Getahun Y., Zebene A., Z. Solomon, "Wood Production and Management of Woody Species in Homegardens Agroforestry: The Case of Smallholder Farmers in Gimbo District, South West Ethiopia", International Journal of Natural Sciences Research, vol.2, no. 10, pp. 165-175, 2014.

[20]Getu A., Zemede A., K. Ensermu, "C.africana (Boraginaceae) in Ethiopia: A Review on Its Taxonomy, Distribution, Ethnobotany and Conservation Status", International Journal of Botany Studies, vol.1, no.2, pp. 38-46, 2016.

[21] Jiregna G., Rozanov A., N. Legesse, "Response of Seedlings of Two Eucalyptus and Three Deciduous Tree Species from Ethiopia to Severe Water Stress", Forest Ecology and Management, vol. 201, no. 1, pp. 119-129, 2004. https://doi.org/10.1016/j.foreco.2004.07.009

[22] J.B. Leiju, "Ecological Recovery of an Afromontane Forest in South - Western Uganda", African Journal of Ecology, vol.42, no.1, pp. 64-69, 2004. https://doi.org/10.1111/j.1365 $-2028.2004 .00463 . x$

[23] K. Bereket, "Community Wealth-Ranking and Household Surveys: An Integrative Approach", Journal of Development Studies, pp. 1-22, 2009. https://doi.org/10.1080/0022038090 2935832

[24] Mellisse B.T,, van de Ven G.W.J., Giller K.E., K. Descheemaeker,. "Home garden system dynamics in Southern Ethiopia", Agroforestry Systems, vol.92, no.6, pp. 1579-1595,2018.https://doi.org/10.1007/s10457-017-0106-5

[25] N. Mesele, “Trees Management and Livelihoods in Gedeo's Agro forests, Ethiopia; A B Academic Publishers, Helsinki University; Great Britain", Forests, Trees and Livelihoods, vol.17, no.2, pp. 157-168, 2007. https://doi.org/10.1080/147 28028.2007.9752591

[26] Muktar M., Alemayehu B., R. Muktar, "Influence of Scattered C.africana and Croton macrostachyus Trees on Selected Soil Properties, Microclimate and Maize Yield in Eastern Oromia, Ethiopia", American Journal of Agriculture and Forestry, vol. 6, no.6, pp. 253-262, 2018. https://doi.org/10.11648/j.ajaf.20180606.23

[27] R. Reta, "Diversity and Conservation Status of Some Economically Valued Indigenous Medicinal Plants in Hawassa College of Teacher Education Campus, Southern Ethiopia”. International Journal of Advanced Research, vol.1, no. 3, pp. 308-328, 2013. https://doi.org/10.1080/21513732. 2014.973449

[28] Saikia P., M.L. Khan, "Homegardens of upper Assam, northeast India: a typical example of on farm conservation of Agarwood (Aquilaria malaccensis Lam.)", International journal of biodiversity science, Ecosystem services and management, vol.10, no. 4, pp. 262-269, 2014.

[29] SDCPS, Sidama Development Corporation, Planning and Statistics.Sidama Development Corporation, Planning and Statistics bulletin, 2000. (Accessed 03 March 2021).

[30] Sunderland T., J. Nkefor, "Conservation through Cultivation: A Case Study: The Propagation of Pygeum-Prunus africana", Journal of Tropical Agriculture, vol.17, no.4, pp. 5-13, 1997.

[31] S.J. Wright, The Future of Tropical Forests", Annals of the New York Academy of Sciences, vol.1195, no.1, pp. 1-27, 2010.https://doi.org/10.1111/j.1749-6632.2010.05455.x

[32]Zebene A., G.I. Agren, "Farmers' local knowledge and topsoil properties of agroforestry practices in Sidama, Southern Ethiopia", Agroforest Syst, vol.71, pp.35-48, 2007. https://doi.org/10.1007/s10457-007-9087-0 